\title{
Children Forgotten in School Vehicles
}

\author{
Sirada Puetpaiboon ${ }^{1} \cdot$ Therdpong Thongseiratch $^{1}$ [D
}

Received: 2 June 2021 / Accepted: 19 August 2021/ Published online: 1 September 2021

(c) Dr. K C Chaudhuri Foundation 2021

To the Editor: The death of a child forgotten in a parked vehicle (CPV) is an uncommon but usually wellpublicized event [1]. While the existing literature has focused on descriptive epidemiology of parked-vehicle deaths in general [2], a large proportion of these deaths occur under care by teachers or school drivers, suggesting an opportunity to reduce the risk of these preventable events via structural and institutional approaches. We conducted a systematic review to identify cases of children being forgotten in school vehicles (CSV) in the worldwide peerreviewed literature, three databases including PubMed, Scopus, and Web of Science using the specific search terms "parked vehicles" and "child," and in websites in 47 Asian countries. We identified 10 cases of CSV $\{8$ from Thailand and 2 cases from India\} [3]. We found that all identified cases of CSV occurred due to children being forgotten, and all incidents occurred from April to August, which are months in the summer or wet season in Thailand and India. All cases were left more than $2 \mathrm{~h}$ and resulted from being forgotten by the teacher or school driver. The median age of children was 3. Eight incidents occurred in the first school semester. Our findings indicate that these events occur in children slightly older than those occurring in private vehicles, and they show a notable seasonal effect that is not driven by temperature alone but by occurring early in the academic calendar. In the tropics, we hypothesize that the incidents of CSV may be the result of school semester, not season alone. The characteristics of the cases documented in Thailand and India reveal that seasonal public-education campaigns offering a basis for future work in developing prevention strategies, may miss part of the root problem [4].

\section{Declarations}

Conflict of Interest None.

\section{References}

1. Naumann RB, Dellinger AM, Zaloshnja E, et al. Incidence and total lifetime costs of motor vehicle-related fatal and nonfatal injury by road user type, United States, 2005. Traffic Inj Prev. 2010;11:353-60.

2. Williams CA, Grundstein AJ. Children forgotten in hot cars: a mental models approach for improving public health messaging. Inj Prev. 2017. https://doi.org/10.1136/injuryprev-2016-042261.

3. Siddiqui GF, Singh MV, Shrivastava A, et al. Children left unattended in parked vehicles in India: an analysis of 40 fatalities from 2011 to 2020. J Trop Pediatr. 2021;67:fmaa075.

4. Ho K, Minhas R, Young E, et al. Paediatric hyperthermia-related deaths while entrapped and unattended inside vehicles: the Canadian experience and anticipatory guidance for prevention. Paediatr Child Health. 2020;25:143-8.

Publisher's Note Springer Nature remains neutral with regard to jurisdictional claims in published maps and institutional affiliations.

Therdpong Thongseiratch

ttherd@gmail.com

1 Department of Pediatrics, Faculty of Medicine, Child

Development Unit, Prince of Songkla University,

Songkhla 90110, Thailand 